\title{
Midst of COVID-19 Crisis - Lookout for One Another to Practice Humanity!
}

The coronavirus disease 2019 (COVID-19) pandemic has brought anxiety and panic among people across the world.

Case: Ms. S, our departmental secretary, a young and cheerful lady, called up at the end of her shift, crying and wanting to urgently get tested to know if she is infected with severe acute respiratory syndrome-coronavirus-2 (SARS-CoV-2). One of the radiotherapy staff had been diagnosed with SARS-CoV-2 infection, and it was the reason for her panic. The radiotherapy and the medical oncology departments shared the same floor, leading her to think that she would be infected. Her world had come crashing down and was difficult to calm her down.

This real-life incident at our tertiary care center set me thinking about the fear and panic this virus had created despite all the training that the staff was given for dealing with COVID-19. This made me wonder what must be going through in a layperson's mind or among people in the society where suspected or infected people are kept under home quarantine? The nationwide lockdown, gave the much-needed time to go through the literature and gather my thoughts on how to help such people during these troubled times.

\section{The Virus and the Disease}

COVID-19, a highly infectious disease, is caused by the SARS-CoV-2. It was first identified in the Hubei province of Wuhan, China, in December 2019.[1] The coronavirus outbreak was declared as a Public Health Emergency of International Concern by the World Health Organization (WHO) on January 30, 2020, and a pandemic on March 12, 2020. ${ }^{[2,3]}$ The early reports from China suggested that people get infected mainly by close contact with another infected person. Activities such as coughing, sneezing, or even talking loudly produce small droplets, which can either directly infect the other person in close contact, or indirectly by touching contaminated surfaces where the virus may survive up to 72 hours. ${ }^{[4]}$ The virus shedding can be detected from day 1 of the illness up to on an average of 4.6 days, but can be shed up to 19 days after the symptoms first appear..$^{[4]}$ The number of people infected has regional variation because of several factors such as total numbers tested, health-care infrastructure and expertise, available treatment options, time elapsed since the outbreak, and the population demographics.

Majority of the symptomatic COVID-19 patients have fatigue, fever, and dry cough. However, some patients have also reported flu-like symptoms, especially nasal congestion, malaise, sore throat, or atypical symptoms such as headache, anosmia, loss of taste, and diarrhea. In majority of the patients, these symptoms are mild, while some remain asymptomatic. ${ }^{[5,6]}$ About $80 \%$ of those who get infected, recover without needing hospitalization. However, $10 \%-15 \%$ of the infected people become seriously ill and develop difficulty in breathing. ${ }^{[5]}$ Several publications have revealed that elderly, and those with comorbidities such as "uncontrolled" hypertension or diabetes, cardiovascular diseases, or cancer, are more likely to develop serious illness. ${ }^{[7-10]}$ The WHO has advised that people with fever, cough, and dyspnea should be evaluated by a physician. ${ }^{[5]}$

\section{Diagnosis}

The current standard of diagnosis is by nucleic acid amplification tests such as the real-time reverse transcriptase-polymerase chain reaction in a sample taken from, preferably, the nasopharynx..$^{[11,12]}$ Some studies suggest higher sensitivity of non-contrast computed tomography chest imaging, which can be used as an adjunct rather than independent testing. ${ }^{[13,14]}$ The $\operatorname{IgM} / \operatorname{IgG}$ antibody test cannot be relied upon for diagnosis of acute infection (due to low specificity and cross-reactivity with SARS-CoV) but can be used for epidemiological purposes. Currently, no antibody tests are approved for use in India.

\section{Treatment for Coronavirus Disease 2019}

Multiple antivirals and targeted therapies have been used, but none of them have been able to successfully treat the patients with severe form of the disease. Therefore, the emphasis is on prevention of infection by frequent hand washing, maintaining physical distance from people with symptoms of COVID-19, maintaining coughing etiquette, and avoiding traveling to areas known to have higher infection rates and rapid community transmission of SARS-CoV-2 ${ }^{[5,6]}$ Furthermore, there is no vaccine that has received approval for use against SARS-CoV-2, causing increased levels of stress and anxiety with the fear of getting infected, resulting in death. The following are some brief guidelines that may be followed to help during different situations as abstracted from various sources such as advisories from the Ministry of Health and Family Welfare (MOHFW), WHO, and other international agencies. While these are helpful, it is important to remember that the pandemic along with the guidelines change rapidly and we urge everyone to be updated with the latest information from the local authorities.

\section{For the infected patient}

1. Patients with symptoms such as respiratory distress or severe fatigue would need hospitalization for active treatment. However, as per the MOHFW, all such people should be isolated in community quarantine facilities for containing the spread 
2. After testing positive, retesting may be done after 14 days and subsequently every 4-7 days till a negative report is obtained and that is confirmed again after $24 \mathrm{~h}$. Patients would be discharged from the facility only once two consecutive tests results are negative

3. While in isolation, patients must observe physical distancing and minimize contact

4. Patients are allowed to take cell phones, laptops, books, etc., with them, which would help in keeping them updated, informed, and entertained

5. Even though outdoor activities are restricted, physical activities such as yoga and relaxation exercises can be practiced

6. Smoking, chewing tobacco, and alcohol consumption are strictly prohibited at such facilities, andit may help to carry nicotine chewing gums for people with physical addiction to tobacco

7. Food is provided at the isolation facility; however, patients are allowed to carry some snacks or electric kettle for tea and coffee

8. Patients on daily medication for their comorbidities are required to inform the health authorities regarding the same and bring them along for use during their isolation

9. Patients are also required to inform the health authorities about allergies to any food items or medications

10. It is important to alert the physician about any worsening of symptom (s) or development of any new symptom (s) so that timely treatment can be provided or if needed, shifted to more intensive monitoring facilities.

For family members or close contacts of infected patients

1. All those who have come within $1 \mathrm{~m}$ of an infected person for up to $15 \mathrm{~min}$ or more are considered as primary contacts and need to be quarantined and tested for infection even if asymptomatic between day 5 and day 14 since the contact. Those that test negative should be retested if they become symptomatic ${ }^{[15]}$

2. Strict quarantine should be executed for all such contacts so that the secondary contacts can be limited and the chain of transmission can be broken

3. There is no need to self-medicate. If anyone in the family develops COVID-19-related symptoms, then their testing would be done and appropriate treatment will be given

4. The virus can remain active on some surfaces up to $72 \mathrm{~h}$. Thus, disinfection of surfaces that are frequently touched, implementing frequent hand hygiene and limiting touching eyes, nose, and mouth, is considered crucial $^{[6]}$

5. Patient's family members can become victims of social isolation and stigma after infected case (s) are detected from the family. The only way to prevent that is creating awareness in the society about COVID-19, its routes of transmission, and preventive measures.

\section{For people living in the neighborhood}

1. Wearing a face mask helps to reduce the aerosol production and contamination; hence, it is recommended for use in public places ${ }^{[5]}$

2. It is important to be aware of the COVID-19 hotspots. Traveling should be avoided for those at high risk of severe disease (the elderly, those with chronic lung diseases, patients with a history of cardiovascular diseases, and those with uncontrolled diabetes or hypertension)

3. Avoid contact with people showing symptoms of COVID-19

4. Do not visit the family or people that are under home quarantine

5. Housing societies need to be compassionate toward those under quarantine and the health care, security, and sanitation personnel, who come for contact tracing, evaluation, and testing for COVID-19

6. Non-compliance with the quarantine, restriction, lockdown and non-cooperation with health care, security, and sanitation personnel make you liable for getting arrested with charges under the National Security Act ${ }^{[16]}$

7. Forwarding messages on social media without verifying them can lead to unnecessary panic and misconceptions and hence should be discouraged. Visit government health sites for authentic news and updates

8. Avoid non-essential travel and use of public transport or toilets $^{[17]}$

9. Avoid visits to hospitals or labs for minor or chronic ailments; contact hospital to know if telemedicine options are available.

\section{The Brighter Side}

Till mid-august, even with $>2.7$ million confirmed cases of COVID-19 in India, nearly 2 million have recovered (approximately $70 \%$ recovery rate). A very high number of deaths have been reported from developed countries like the USA $(>170,000)$ and the UK $(>41,000)$ and some developing countries like Brazil $(>110,000)$ and Mexico $(>53,000)$. The number of such deaths in India $(<53,000)$ is compared to the USA far less. ${ }^{[18]}$ It is still unclear why the COVID-19 impact has dulled in the Indian population. The nationwide strategic lockdown may have contributed to that effect, with the other theories being the cross-protection by Bacillus Calmette-Guérin vaccination by upregulating ACE receptors and downregulating ACE-2 receptors, ${ }^{[19]}$ higher ambient temperatures and humidity, ${ }^{[20,21]}$ or may be geo-ethnic differences. The containment policies of the Indian government including preparedness and response measures strategies for COVID-19 have been appreciated by the WHO. The strict adherence to lockdown, creating awareness on a variety of television and social media platforms, pooled sampling, detailed contact tracing, involving government and private labs for testing, providing daily update on containment measures taken by 
the government, community engagement, ensuring hospital preparedness, research and development on vaccines, treatments, and personal protective equipment have been exceptional. This pandemic is humbling as it reminds us of our vulnerability across all social, economic, ethnic, and racial backgrounds. It has also united the different countries in their effort to combat the virus and contain the pandemic. This pandemic has forced people on the planet to pause and reflect on the impact of their invasion into the natural habitats of the animal and the dynamics of these interactions between humans and wildlife. If this reflection results in adopting more ecofriendly policies, then its impact would be far reaching.

P. S. Ms. S finally got her swab testing done. Her reports are awaited. Hopefully, she will be tested negative. She was given educational counseling about the COVID-19. She is calm and equipped to deal with it.

Financial support and sponsorship

Nil.

\section{Conflicts of interest}

There are no conflicts of interest.

\section{Reetu Jain ${ }^{1}$, Rima Pathak ${ }^{2}$, Padmaj Kulkarni ${ }^{3}$, Prashant Mehta ${ }^{4}$, Tilak TVSVGK ${ }^{5}$, Jyoti Bajpai ${ }^{6}$}

${ }^{I}$ Department of Medical Oncology, Jaslok Hospital, Mumbai, Maharashtra, India, ${ }^{2}$ Department of Radiation Oncology, Tata Memorial Centre, Homi Bhabha National Institute, Mumbai, Maharashtra, India, ${ }^{3}$ Department of Medical Oncology, Dinanath Mangeshkar Hospital, Pune, Maharashtra, India, ' ${ }^{2}$ Department of Medical Oncology/Hematology/ BMT, Asian Institute of Medical Sciences, Faridabad, Haryana, India, ${ }^{5}$ Department of Internal Medicine, Armed Forces Medical College, Pune, Maharashtra, India, ${ }^{6}$ Department of Medical Oncology, Tata Memorial Centre, Homi Bhabha National Institute, Mumbai, Maharashtra, India

Address for correspondence: Dr. Jyoti Bajpai, Department of Medical Oncology, Room No. 1115, $11^{\text {th }}$ Floor, Homi Bhabha Block, Tata Memorial Centre, Parel, Mumbai - 400 012, Maharashtra, India. E-mail:dr_jyotibajpai@yahoo.co.in

Submitted: 27-Apr-2020 Accepted in Revised Form: 19-May-2020 Published: 29-Aug-2020

\section{References}

1. Tsang J, Bajpai J. Novel coronavirus infection - Knowns and unknowns with particular reference to oncology - Combating against COVID-19 with "COVID." Indian J Med Paediatr Oncol 2020;41:112-20.

2. World Health Organization. Statement on the Second Meeting of the International Health Regulations (2005) Emergency Committee regarding the Outbreak of Novel Coronavirus (2019-nCoV). World Health Organization; 2020. Available from: https://www.who.int/news-room/deta il/30-01-2020-statement-on-the-second-meeting-of-the-int ernatio nal-health-regulations-(2005)-emergency-committee-regarding-th e-outbreak-of-novel-coronavirus-(2019-ncov). [Last accessed on 2020 Apr 22].

3. World Health Organization. WHO Announces COVID-19
Outbreak a Pandemic. World Health Organization; 2020. Available from: http:/www.euro.who.int/en/health-topics/ health-emergencies/coronavirus-covid-19/news/news/2020/3/ who-announces-covid-19-outbreak-a-pandemic. [Last accessed on 2020 Apr 22].

4. van Doremalen N, Bushmaker T, Morris DH, Holbrook MG, Gamble A, Williamson BN, et al. Aerosol and surface stability of SARS-CoV-2 as compared with SARS-CoV-1. N Engl J Med 2020;382:1564-7.

5. World Health Organization. Q\&A on Coronaviruses (COVID-19); 2020. Available from: https:// www.who.int/news-room/q-a-d etail/q-a-coronaviruses. [Last accessed on 2020 Apr 09].

6. Adhikari SP, Meng S, Wu YJ, Mao YP, Ye RX, Wang QZ, et al. Epidemiology, causes, clinical manifestation and diagnosis, prevention and control of coronavirus disease (COVID-19) during the early outbreak period: A scoping review. Infect Dis Poverty 2020;9:29.

7. Velavan TP, Meyer CG. The COVID-19 epidemic. Trop Med Int Health 2020;25:278-80. Available from: http://www.ncbi.nlm.nih. gov/pubmed/32052514. [Last accessed on 2020 Apr 22].

8. Wu Z, McGoogan JM. Characteristics of and important lessons from the coronavirus disease 2019 (COVID-19) outbreak in China: Summary of a report of 72314 cases from the Chinese Center for Disease Control and Prevention. JAMA 2020;323:1239-42.

9. Zhou F, Yu T, Du R, Fan G, Liu Y, Liu Z, et al. Clinical course and risk factors for mortality of adult inpatients with COVID-19 in Wuhan, China: A retrospective cohort study. Lancet 2020;395:1054-62.

10. Liang W, Guan W, Chen R, Wang W, Li J, Xu K, et al. Cancer patients in SARS-CoV-2 infection: A nationwide analysis in China. Lancet Oncol 2020;21:335-7.

11. Wang W, Xu Y, Gao R, Lu R, Han K, Wu G, et al. Detection of SARS-CoV-2 in different types of clinical specimens. JAMA 2020;323:1843-4.

12. U.S. Food and Drug Administration: FAQs on Diagnostic Testing for SARS-CoV-2. FDA; 2020. Available from: https:// www.fda.gov/medical-devices/emergency-situations-med ical-devices/faqs-diagnostic-testing-sars-cov-2. [Last accessed on 2020 Apr 22].

13. Raptis CA, Hammer MM, Short RG, Shah A, Bhalla S, Bierhals AJ, et al. Chest CT and coronavirus disease (COVID-19): A critical review of the literature to date. AJR Am J Roentgenol 2020;1-4. Available from: http://www.ncbi.nlm.nih.gov/pub med/32298149. [Last accessed on 2020 Apr 22].

14. Fang Y, Zhang H, Xie J, Lin M, Ying L, Pang P, et al. Sensitivity of Chest CT for COVID-19: Comparison to RT-PCR. Radiology 2020;200432. doi: 10.1148/radiol.2020200432. Online ahead of print.

15. Department of Health Research IC of MR: Revised Strategy of COVID19 testing in India (Version 3, dated 20/03/2020); 2020. Available from: https://www.mohfw.gov.in/pdf/ ICMRrevisedtestingst rategyforCOVID.pdf. [Last accessed on 2020 Apr 24].

16. Covid-19 Outbreak: NSA against Lockdown Violators - India News - Hindustan Times. Available from: https://www. hindustantimes.com/india-news/covid-19-outbreak-nsa-agai nst-lockdown-violators/story-t7f4r5EwZhk8MHY8D59U2O. html. [Last accessed on 2020 Apr 23].

17. Ministry of Health and Family Welfare. Detail Question and Answers on COVID-19 for Public. Ministry of Health and Family Welfare; 2020. Available from: https://www.mohfw.gov. in/. [Last accessed on 2020 Apr 23]. 
18. World Health Organization. WHO COVID-19 Dashboard. World Health Organization; 2020. Available from: https://covid19.who. int/. [Last accessed on 2020 Apr 23].

19. Does BCG bolster one's Immunity against COVID-19? BMJ. Available from: https:/www.bmj.com/content/368/bmj.m1252/ rr-4. [Last accessed on 2020 Apr 23].

20. Sun Z, Thilakavathy K, Kumar SS, He G, Liu SV. Potential factors influencing repeated SARS outbreaks in China. Int $\mathrm{J}$ Environ Res Public Health 2020;17:1633.

21. Liu J, Zhou J, Yao J, Zhang X, Li L, Xu X, et al. Impact of meteorological factors on the COVID-19 transmission: A multi-city study in China. Sci Total Environ 2020;726:138513.
This is an open access journal, and articles are distributed under the terms of the Creative Commons Attribution-NonCommercial-ShareAlike 4.0 License, which allows others to remix, tweak, and build upon the work non-commercially, as long as appropriate credit is given and the new creations are licensed under the identical terms.

\begin{tabular}{|l|l|}
\hline \multicolumn{2}{|c|}{ Access this article online } \\
\hline Quick Response Code: & Website: \\
& www.ijmpo.org \\
\cline { 2 - 2 } & DOl: \\
\hline
\end{tabular}

How to cite this article: Jain $R$, Pathak $R$, Kulkarni $P$, Mehta $P$, Tilak TVSVGK, Bajpai J. Midst of COVID-19 crisis - Lookout for one another to practice humanity! Indian J Med Paediatr Oncol 2020;41:446-9. 